Revista Oficial del Poder Judicial

ÓRGANO DE INVESTIGACIÓN DE LA CORTE SUPREMA DE JUSTICIA DE LA REPÚBLICA DEL PERÚ

Vol. 11, n. ${ }^{\circ} 13$, enero-junio, 2020, 197-239

ISSN versión impresa: 1997-6682

ISSN versión electrónica: 2663-9130

DOI: https://doi.org/10.35292/ropj.v11i13.44

\title{
Repensar la justicia en tiempos de emergencia y de oportunidades
}

Rethinking the justice system in times of emergency and its opportunities

0 (0)

HELDER DOMÍNGUEZ HARO

Centro de Investigaciones Judiciales del Poder Judicial

(Lima, Perú)

Contacto: hdominguez@pj.gob.pe

https://orcid.org/0000-0003-4617-8341

\section{RESUMEN}

La crisis y la declaratoria de emergencia institucional y funcional dentro del sistema de justicia ha originado modificaciones constitucionales y legales, y la creación del Consejo para la Reforma del Sistema de Justicia como una nueva oportunidad de cambio para repensar la función de la magistratura. Dentro de ese marco, el contexto actual, y desde una reflexión crítica, el autor repasa algunas acciones y propuestas reformistas que debe tener en cuenta el referido Consejo. Para ello, identifica los antecedentes históricos y documentales desde la creación de una comisión de reforma judicial ocurrida en 1958; y si bien el fenómeno cíclico de reordenar 
la justicia se ha expresado haciendo y deshaciendo comisiones, como analiza el autor, hay razones para pensar que el Consejo para la Reforma del Sistema de Justicia es una alternativa para la transformación posible de «lo judicial» y de las demás instituciones tutelares dentro de los parámetros de una justicia democrática y del constitucionalismo democrático, hacia el rescate de la confianza ciudadana y de la calidad del servicio de justicia.

Palabras clave: sistema de justicia, Poder Judicial, reforma judicial, justicia democrática, emergencia institucional.

\section{ABSTRACT}

The institutional and functional crisis and the declaration of state of emergency have created a new legal framework to reform the old justice system. The new context serves to rethink the justice system and it is the opportunity to change the legal practices and institutions. For example, it was created the «Consejo para la Reforma del Sistema de Justicia».

This essay reviews the previous proposals to reform the "Consejo». It analyzes the judicial reform of 1958. One conclusion is that, probably, the different reform to the justice system does not benefit anything; but there is a reason to think that the "Consejo para la Reforma del Sistema de Justicia» will be a real change of the judicial system. It is for his legal design. The legal framework of the "Consejo» uses some democratic and constitutional norms. These serve to reassess the trust of citizens and the quality of the justice system.

Key words: justice system, Judicial Power, judicial reform, emergency.

Recibido: 25/05/2020 Aceptado: 10/06/2020 


\section{INTROITO}

Sobre la reforma judicial se ha escrito en demasía y de toda envergadura, como es el caso de la experiencia en América Latina y en el Perú (frondosa bibliografía) ${ }^{1}$, al punto de haberse tratado de reemplazar o asociar la voz «reforma judicial» con otras palabras de acuerdo con cada momento histórico, llámese modernización, reestructuración, refundación, reorganización, transformación o cambio. Pese a ello, creemos que es posible recuperar el sentido de una auténtica renovación judicial estructural y multidimensional, aunque muchas veces se considere como una expresión trillada o deslegitimada por la existencia en la historia peruana de reformas inconclusas, insuficientes, torcidas, imposibles o, peor aún, de pseudorreformas. En la hora contemporánea, sea cual sea su denominación, su encuadramiento corresponde - absolutamentedesde un formato de democracia constitucional o dentro de los parámetros del constitucionalismo democrático para el replanteamiento y fortalecimiento judicial, como poder estataljurisdiccional; y, claro está, el rescate de la confianza ciudadana ${ }^{2}$.

La creación del Consejo para la Reforma del Sistema de Justicia - hace un poco más de un año mediante la Ley n. ${ }^{\circ} 30942$ - como consecuencia de la grave crisis del sistema de justicia - ocurrida hace aproximadamente dos años-, que originó su declaración de emergencia (institucional y funcional) ${ }^{3}$, y replanteada naturalmente por la emergencia sanitaria y las secuelas lamentables del coronavirus (sobre todo la pérdida de vida de muchos peruanos), exige desafíos y hechos concretos por parte de cada una de las instituciones tutelares;

1 Leáse Domínguez (2019, pp. 374-438).

2 Para mayor información sobre el sustento democrático «con» Constitucion, véase Domínguez (2018).

3 En el 2018, el Congreso de la República declaró en emergencia al Consejo Nacional de la Magistratura y el mismo Poder Judicial se declaró en emergencia, como se verá más adelante. 
por cuanto la indiferencia ante los problemas de las personas, al activar el sistema de justicia, es también un virus que toca y trastoca la vida humana.

La reforma judicial iniciada por el referido órgano colegiado e interinstitucional debe andar por el camino de la «ideología de la justicia democrática». No es casual, solo como muestra, que la Cumbre Judicial Iberoamericana, como espacio de cooperación e intercambio de experiencias entre los poderes judiciales de los veintitrés países de la Comunidad Iberoamericana de Naciones, tenga como principal objetivo la «adopción de proyectos y acciones concertadas, desde la convicción de que la existencia de un acervo cultural común constituye un instrumento privilegiado que, sin menoscabo del necesario respeto a la diferencia, contribuye al fortalecimiento del poder judicial y, por extensión, del sistema democrático [cursivas añadidas]» (Cumbre Judicial Iberoamericana, s. f., párr. 2). Objetivo que debe ir de la mano con el compromiso para la adopción y el cumplimiento en las respectivas esferas de acción de los poderes judiciales iberoamericanos, de lo que se conoce como la Agenda 2030 y los Objetivos de Desarrollo Sostenible (ODS) en torno a facilitar el acceso a la justicia en clave inclusiva planteado por las Naciones Unidas ${ }^{4}$.

En ese sentido, permítasenos repensar algunas líneas bases a la luz de las circunstancias particulares hoy en día; y para una mejor comprensión de nuestro optimismo por la transformación posible de «lo judicial», debemos conocer de dónde venimos y cómo estamos en este crucial tema desde - seguimos insistiendo- la perspectiva democrática constitucional y la función política-social del juez ${ }^{5}$.

4 Consultar Consejo Nacional de Justicia (2019).

5 Debe precisarse que los puntos de vista expresados, los errores u omisiones, son de responsabilidad de mi persona y no representan ni comprometen necesariamente los puntos de vista del Poder Judicial. 


\section{LA REFORMA DEL ESTADO A TRAVÉS DE LA REFORMA JUDICIAL}

\subsection{Historia mínima de marchas y contramarchas: un fenómeno cíclico}

En el Perú, no cabe duda y como veremos en los apartados siguientes, han existido diversas formas de organizar y reorganizar el Poder Judicial desde el siglo XIX; sin embargo, nos focalizaremos a partir de la década de los sesenta del siglo XX hasta la fecha. Precisamente, siguiendo la lógica de la especialista estadounidense en estos temas, Linn Hammergren (2004), quien ha indicado que «Hasta los años sesenta, el poder judicial peruano funcionó en forma más o menos acorde con las demandas de la sociedad» (p. 293); en consecuencia, a partir de estos tiempos hasta nuestros días el debate ha ido creciendo entre los entendidos en la materia, expertos y especialistas ${ }^{6}$. De hecho, la reforma judicial peruana fue una de las primeras en América Latina. Utilizando prestada la metáfora marina de las llamadas olas democratizadoras de Huntington, se habla de diferentes «olas de reformas» democráticas y no democráticas en los últimos sesenta años de vida republicana ${ }^{7}$.

a) En el siglo XX, la década de los sesenta arrastra consigo el trabajo de una Comisión para la Reforma del Poder Judicial creada por la Ley n. ${ }^{13036}$, de noviembre de 1958, pues en

6 En suelo nacional, a diferencia de otras especialidades, como constitucionalistas, civilistas, penalistas, laboralistas o de derecho corporativo, hay pocos expertos en reforma judicial y en metodología para la reforma judicial. El lenguaje de los procesos de reestructuración en el ámbito de la judicatura requiere una gran dosis de experiencia. El de los profesionales de la reforma es un campo que merece un capítulo adicional y que será desarrollado en otra ocasión.

7 Dos especialistas peruanos, Luis Pásara y Javier de Belaunde, no dan crédito a la reforma de los sesenta. De hecho, consideran que en la segunda mitad del siglo XX han habido solo dos reformas, en 1976 y en 1996; y ambos profesionales han sido protagonistas de la reforma de los setenta en el ámbito de la capacitación judicial. 
noviembre de 1960 alcanzó al Poder Ejecutivo el proyecto de reforma sobre la creación del Consejo Nacional de la Magistratura y modificaciones a la Ley Orgánica del Poder Judicial, en el marco de un gobierno democrático. Posteriormente, entrará en vigencia una avanzada Ley Orgánica del Poder Judicial, Decreto Ley n. ${ }^{\circ} 14605$, de julio de 1963, dada por la Junta de Gobierno (constituida en julio de 1962), que sustituye a la antigua Ley n. ${ }^{\circ} 1510$ de 1911, después de cincuenta y dos años de existencia.

b) La reforma militar de la década de los setenta es producto del golpe de Estado del 3 de octubre de 1968. Y después de más de un año de aparente normalidad con la judicatura, a través del Decreto Ley n. ${ }^{\circ}$ 18060, del 23 de diciembre de 1969, se declara en reorganización el Poder Judicial y se crea el Consejo Nacional de Justicia (miembros designados por la Junta de Gobierno) para la selección y permanencia de los magistrados y cuya consagración a escala constitucional como Consejo Nacional de la Magistratura se da - diez años después - con la carta fundamental de 1979, un cambio radical dentro del modelo de organización judicial. En esta primera fase se publica el Plan Inca, que trata del Poder Judicial reformado. Proceso de «reforma» que será continuado con la Comisión de Reforma Judicial a cargo del presidente de la Corte Suprema de Justicia, creada por el Decreto Ley n. ${ }^{\circ} 21307$, del 11 de noviembre de 1975, y luego - a propuesta de la Corte Suprema de Justicia - por el Centro de Investigaciones Judiciales, dirigido por un Consejo de Gobierno presidido por el presidente de la Corte Suprema de Justicia, según el Decreto Ley n. ${ }^{\circ} 22422$, del 16 de enero de 1979. Ambos esquemas corresponden a la segunda fase del Gobierno dictatorial, dentro del contexto del Plan Túpac Amaru del Gobierno Revolucionario de la Fuerza Armada, en su parte pertinente sobre administración de justicia. Decisiones manu militari en todo su esplendor. 
c) Los años ochenta se inician con la entrada en vigencia de la Constitución Política de 1979, que introduce un nuevo modelo y proceso de reinstitucionalización y de reconstrucción del sistema de justicia en su máxima expresión normativa. El Poder Judicial, por un lado, ve disminuido una vez más su campo de acción, por cuanto la selección, designación, ratificación y destitución de magistrados las asume el denominado Consejo Nacional de la Magistratura (CNM). Aparece de un modo autónomo el Ministerio Público, entra en acción nada menos que el Tribunal de Garantías Constitucionales y se resalta constitucionalmente la «jurisdicción» paralela e independiente con los tribunales especializados en materia militar y arbitral.

Por otro lado, se eliminan los fueros privativos de la década pasada (laboral y agrario). El Poder Judicial mantiene el gobierno judicial, el régimen disciplinario y asume la tarea reformista a través de la Presidencia del Poder Judicial y la Sala Plena de la Corte Suprema de Justicia, con la participación del Consejo de Gobierno del Centro de Investigaciones Judiciales, dependiente de la Corte Suprema de Justicia, y con el apoyo de las diferentes comisiones de trabajo por especialidad. Y conjuntamente con el Ministerio de Justicia y el Ministerio Público se formula un proyecto de modernización y fortalecimiento del sistema judicial peruano. No obstante, lo prescrito por la undécima disposición transitoria de la Constitución de 1979 habilitando una nueva Ley Orgánica del Poder Judicial, no se materializó en esta década.

d) La llamada reforma y modernización de la justicia de los noventa se inicia normativamente con una nueva y moderna Ley Orgánica del Poder Judicial sancionada por el Decreto Legislativo n. ${ }^{\circ} 767$, del 29 de noviembre de 1991 (en reemplazo del Decreto Legislativo n. $^{\circ} 612$, del 26 de julio de 1990, que nunca entró en vigencia). Y tras el quiebre del régimen constitucional ocurrido el 5 de abril de 1992, al día siguiente por Decreto Ley n. ${ }^{\circ} 25418$, 
Ley de Bases del Gobierno de Emergencia y Reconstrucción Nacional, se declara en reorganización integral el Poder Judicial, el Tribunal de Garantías Constitucionales, el Consejo Nacional de la Magistratura, el Ministerio Público y la Contraloría General de la República. El Decreto Legislativo n. ${ }^{\circ} 767$ es sustantivamente modificado por el Decreto Ley n. ${ }^{\circ} 25869$, del 18 de noviembre de 1992, en cuanto a las funciones y atribuciones de la Sala Plena de la Corte Suprema de Justicia, del Consejo Ejecutivo (en sustitución del Consejo de Gobierno) y la Oficina de Control de la Magistratura (OCMA) - en reemplazo de la Oficina General de Control Interno-; ambos cuerpos legales fueron compilados por un Texto Único Ordenado aprobado por el Decreto Supremo n. ${ }^{\circ} 017-93-J U S$, y luego modificado por la Ley n. ${ }^{\circ} 26373$ de 1994.

A fines de 1992 el Ministerio de Justicia convoca a una Comisión de Reestructuración del Sistema de Justicia integrada por académicos, exjueces, representantes de los poderes estatales, Colegio de Abogados e instituciones de investigación. Surge transitoriamente el Jurado de Honor de la Magistratura, un órgano ad hoc conformado por profesionales «honorables», creado por la Ley Constitucional del 12 de marzo de 1993, con el objeto de pronunciarse sobre la rehabilitación o no de los magistrados separados de su cargos por el autogolpe, evaluación de los jueces y fiscales supremos provisionales, y convocar a concurso público de jueces y fiscales. Este cesó automáticamente con la instalación y funcionamiento del nuevo Consejo Nacional de la Magistratura regulado orgánicamente con la Ley n. ${ }^{\circ} 26397$ de 1994, acorde con la reciente Constitución de 1993, la misma que mantiene la separación del Poder Judicial y del Ministerio Público, como sucedió con el texto constitucional de 1979.

Con la Ley n. ${ }^{\circ}$ 26546, del 20 de noviembre de 1995, la reforma judicial cambia de timón, aparece la Comisión Ejecutiva del Poder Judicial (CEPJ), que contaba con un secretario ejecutivo 
(titular del pliego). Esta se consolidó mediante la Ley n. ${ }^{\circ} 26623, y$ realizaba las funciones de gobierno y de dirección judicial y la «reestructuración y reorganización integral del Poder Judicial»; asimismo, se suspendieron las labores del Centro de Investigaciones Judiciales (hasta el 2000 aproximadamente). En efecto, seis meses después, mediante la Ley n. ${ }^{\circ} 26623$, de 1996, además de crearse el Consejo de Coordinación Judicial (CCI) por encima del Poder Judicial, el Ministerio Público, el Consejo Nacional de la Magistratura y el Tribunal Constitucional, y de declararse en reorganización el Ministerio Público con la partida de nacimiento de la Comisión Ejecutiva del Ministerio Público (CEMP); dicho CCI quedó en manos finalmente de una suerte de «Consejo Transitorio» encabezado por el presidente de la Comisión Ejecutiva del Poder Judicial mientras durase el período de reorganización judicial y fiscal ${ }^{8}$.

En consecuencia, el sistema de justicia quedó bajo la fórmula: CEPJ-CEMP-CCJ, con el predominio del CEPJ, máxime si mediante la Ley n. ${ }^{\circ} 27009$, del 5 de diciembre de 1998, se dispuso prorrogar el llamado en ese momento «proceso de reorganización y modernización del Poder Judicial y del Ministerio Público» hasta el 31 de diciembre de 2000. En este período se continuaron promulgando diversas leyes que modificaban y sustituían

8 Consejo Transitorio conformado además por el presidente de la Comisión Ejecutiva del Ministerio Público y el presidente del Consejo Nacional de la Magistratura, que ejerció sus funciones hasta el 1 de diciembre de 1998, pudiendo ser prorrogado por acuerdo del Consejo, según la primera disposición transitoria, complementaria y final de la Ley n. ${ }^{\circ}$ 26623. Sin embargo, meses después del mismo año, el Tribunal Constitucional declaró fundada en parte la demanda de inconstitucionalidad interpuesta contra las Disposiciones Transitorias, Complementarias y Finales de la Ley n. ${ }^{\circ}$ 26623, derogando el extremo en cuanto a la prórroga a criterio solo del organismo encargado de la reorganización, entre otros excesos de atribuciones igual de importantes (sentencia emitida el 29 de octubre y publicada el 6 de noviembre de 1996). 
facultades de los diferentes órdenes del sistema de justicia, razón por la cual en 1998 se produce la renuncia de los consejeros del Consejo Nacional de la Magistratura a causa de la Ley n. 26933 del mismo año, al recortarse las facultades disciplinarias de dicho órgano para sancionar a los magistrados supremos del Poder Judicial y del Ministerio Público. Es una década de la presencia de la cooperación internacional y de una inversión aproximada de 100 millones de dólares solamente entre 1996 y el 2000 (Hammergren, 2004, p. 290).

e) Finalmente, un expectante proceso de restructuración y refundación judicial se ve nacer a inicios del siglo actual. La nueva fase de reforma de la justicia toma cuerpo desde el 2003 y nuevamente en el 2018, como a renglón seguido damos cuenta. Un dato relevante y atípico en este período es la no "purga» de magistrados, a diferencia de los demás procesos reformistas - una variable ineludible y dolorosa a lo largo de la historia del Poder Judicial (Basadre, 1983, pp. 320-321; Ramos, 2019, p. 203$)^{9}$ -

Previo al inicio del milenio actual, ante el inminente colapso del Gobierno por los vladivideos de la corrupción publicitados en septiembre de 2000 (se anunció la convocatoria a nuevas elecciones presidenciales y congresales), debe precisarse que mediante la Ley n. ${ }^{\circ}$ 27367, del 4 noviembre de 2000, se desactivan las Comisiones Ejecutivas del Poder Judicial y del Ministerio Público, y asumió la conducción del aparato judicial el llamado Consejo Transitorio del Poder Judicial, y en la fiscalía el Consejo Transitorio del Ministerio Público, a pocos días del inicio del Gobierno de Transición de la República del Perú (22 de noviembre de 2000 al 28 de julio de 2001).

9 En los últimos cincuenta años se produjeron purgas en 1969, 1976, 1980 y 1992. 
Por su corta duración, los Consejos Transitorios solo realizaron medidas de urgencias y diagnósticos específicos que pudieran servir a los nuevos órganos de gobierno judicial y fiscal que iniciarían en el 2001. Con la dación de la Ley n. ${ }^{\circ} 27368$, del 6 de noviembre de 2000, se restablecieron las facultades del Consejo Nacional de la Magistratura y en sus disposiciones transitorias se dispuso la convocatoria a concurso nacional para magistrados; y con la Ley n. ${ }^{\circ}$ 27465, de 2001, se estableció la conformación legal y actual del Consejo Ejecutivo, órgano de gobierno judicial que originariamente fue creado con ese nombre en la reforma de 1992.

\subsection{Siglo XXI: un nuevo ciclo de reformas democráticas}

Ante la marea alta son dos los ciclos «estelares» que marcan el destino de la reforma democrática del sistema de justicia y judicial en el vigente siglo. El primer ciclo reformista a cargo, básicamente, de la Comisión Especial para la Reforma Integral de la Administración de Justicia (CERIAJUS) y del Poder Judicial iniciado en el 2003; y el otro gran momento «estelar» con el Consejo para la Reforma del Sistema de Justicia y el Poder Judicial, ante los graves hechos de corrupción en el ámbito de la justicia desbordada en la mitad de 2018.

Estos períodos de reformas en el 2003 y el 2018, tienen importantes antecedentes y sucesivas acciones desde el 2001 al 2016, y mostraron en su conjunto una "euforia reformista» impostergable. De modo comprimido, damos cuenta de ello de la siguiente manera: el informe final de la Comisión de Planificación de Políticas de Moralización, Eticidad y Anticorrupción del Consejo Transitorio del Poder Judicial (creada en el 2001); el Informe de la Iniciativa Nacional Anticorrupción (INA) promovido por el Ministerio de Justicia (2001); los informes y planes estratégicos y priorizados del Grupo de Trabajo de Alto Nivel para la Modernización del 
Sistema Nacional de la Administración de Justicia (GTAN) (2001); el Plan Justicia del Ministerio de Justicia (2001); los Lineamientos para la Reforma Constitucional, parte pertinente, de la Comisión de Estudio de las Bases de la Reforma Constitucional (2001); la parte pertinente del Informe Final de la Comisión de la Verdad y la Reconciliación (2001); veintiocho políticas de Estado del Acuerdo Nacional (2002); el Informe de la Comisión Especial de Estudio del Plan Nacional de Reforma Integral de la Administración de Justicia del Congreso de la República (2004); el Grupo de Trabajo Iniciativa por la Justicia de la Defensoría del Pueblo-IJU (2004); las propuestas del Consorcio Justicia Viva (2004-2005), de la Asociación de Jueces para la Justicia y la Democracia (JUSDEM) (2004); cuarenta y un medidas para la reestructuración de la administración de justicia acordadas por la Sala Plena de la Corte Suprema de Justicia (2005); los informes de la Comisión de Alto Nivel Anticorrupción (CAN) (2010); ochenta propuestas para retomar la «reforma» de la justicia del Instituto de Defensa Legal (IDL) (2013); y la declaración conjunta e informe del Acuerdo Nacional por la Justicia promovido por el Ministerio de Justicia (2016).

La participación de las entidades cooperantes ha sido $-\mathrm{y}$ es también - un viga indispensable para la modernización de la justicia a través de los distintos programas y proyectos durante el período antes aludido: Proyecto de Mejoramiento de los Servicios de Justicia del Banco Mundial-PMSJ (BM); Proyecto de Apoyo a la Reforma del Sistema de Justicia del Perú (Jusper) de la Comunidad Europea (CE); proyectos de modernización a cargo del Iris Center Perú y Programa Umbral Anticorrupción de la Agencia de los Estados Unidos para el Desarrollo Internacional (USAID); Proyecto de Apoyo al Fortalecimiento del Poder Judicial (PAJPJ) del Programa de las Naciones Unidas para el Desarrollo (PNUD); Programa de Mejoramiento de Acceso a la Justicia y Programa de Modernización del Sistema de Administración de Justicia para la Mejora de los 
Servicios brindados a la población peruana-Accede del Banco Interamericano de Desarrollo (BID); proyectos de la cooperación alemana y canadiense, entre otros ${ }^{10}$.

\subsubsection{Primer ciclo de reestructuración del sistema de justicia}

Corresponde a la Comisión Especial para la Reforma Integral de la Administración de Justicia (CERIAJUS), creada por la Ley n. ${ }^{\circ} 28083$ del 4 de octubre de 2003, su activa participación dentro de este nuevo escenario histórico, que gestó el Plan Nacional de Reforma Integral de la Administración de Justicia en el 2004, incluyendo proyectos específicos de reformas constitucionales y modificaciones legales ${ }^{11}$. A tan importante insumo y referencia inocultable debemos remitirnos por su enfoque integral.

Existen, en efecto, diversos comentarios originados a la luz de dicha ambiciosa receta institucional colectiva de corta duración como resultado de un proceso inédito en determinado sentido. Por ello, para los fines de este trabajo, bastaría señalar como una virtud del plan, el asociar al sistema de justicia y a la reforma judicial indiscutiblemente con la democracia en el ítem A, que a la letra decía: «Democracia es justicia independiente y eficiente: hacia la refundación de la justicia» y también dentro de la misión del sistema

10 En este espacio de tiempo de frenesí reformista, incluso algunas firmas legales se hicieron presentes en determinados proyectos. El Estudio Garrigues de España obtuvo la buena pro para realizar el Proyecto de Modernización de la Justicia en el Perú, financiado por el Banco Interamericano de Justicia (BID) y el staff peruano elegido para apoyar el referido proyecto fue el Estudio Echecopar, cuyo equipo estuvo liderado por el jurista Javier de Belaunde. Situación que nos conduce a una pregunta válida: ¿los estudios de abogados deben encargarse de los proyectos de reforma de justicia?, ¿estamos ante conflictos de intereses?

11 La experiencia sobre este tipo de contribuciones del siglo XXI proviene también de México, para citar un ejemplo, con una especial metodología iniciada con una amplia consulta nacional y que concluyó con el Libro blanco de la reforma judicial. Una agenda para la justicia en México (2006). 
de justicia formulada. Ni en el título ni en el contenido tilda a la democracia de constitucional; sin embargo, se manejaba una lista de ingredientes propios de su fisonomía desarrollados de modo demasiado escueto: «sistema democrático», «Estado constitucional de derecho», "modelo democrático contemporáneo de justicia», «control constitucional», «derechos fundamentales», y sobre el juez un «enfoque político de su rol en la sociedad».

Sin duda, emplear dichas categorías en un mismo texto con un breve repaso de las experiencias de iniciativas de reformas bajo el epígrafe "Antecedentes» a continuación del ítem mencionado, fue un desacierto, al no darle un tratamiento independiente a la ideología democrática como sustento para «volver a fundar» la justicia. Se perdió la ocasión de explayarse sobre la filosofía de la democracia y del derecho como sustento de la reforma del siglo XXI, que probablemente podría haber servido para una mejor comprensión de los actores del sistema y de la ciudadanía.

Igualmente, desde la judicatura se plasmaron documentos y acciones de autorreforma, al haberse declarado en reestructuración el Poder Judicial por acuerdo de la Sala Plena de la Corte Suprema de Justicia del 22 de enero de 2003. Se concibieron documentos de trabajo de envergadura por parte de la Comisión de Magistrados para la Reestructuración del Poder Judicial, formalizada mediante la Resolución n. ${ }^{\circ}$ 035-2003-P-PJ, del 13 de febrero de 2003, y creada por acuerdo de la Sala Plena de la Corte Suprema de Justicia (seis meses antes de la CERIAJUS). Se consensuó el documento-base «Políticas de Estado para el cambio estructural en el Poder Judicial», aprobado por la Sala Plena de la Corte Suprema de Justicia del 12 de abril de 2004, como producto final del Programa Acuerdo Nacional por la Justicia, instituido por la Resolución n. ${ }^{\circ}$ 1912003-P-PJ del 22 de octubre de 2003 con el respaldo de la Corte Suprema de Justicia e instalado en la ciudad de Ayacucho. Ello generó diversos proyectos de leyes y dentro de esta experiencia se 
tuvo la participación democrática y la opinión de autoridades y de la sociedad en audiencias públicas y reuniones técnicas regionales, un hecho inédito en la historia judicial.

El documento-base asumió como principio rector la convicción de que solo la democracia y el Estado de derecho garantizan la plena vigencia de los derechos fundamentales; dentro de la política de «Gobierno y organización descentralizada del Poder Judicial» la promoción de una nueva cultura judicial, con un perfil de juez sensible a su entorno social, socialmente responsable de sus decisiones y con marcos de pensamiento flexible y creativo; y como recomendación para el cumplimiento del ANJ la formación de una red de organismos de la sociedad para una justicia democrática (Grupo Impulsor del Acuerdo Nacional por la Justicia, 2004, pp. 3, 11 y 20).

Este programa se encargó también de colaborar con la CERIAJUS y difundir las propuestas de la Comisión de Magistrados para la Reestructuración del Poder Judicial, y mediante la Resolución n. ${ }^{\circ}$ 109-2003-CE-PJ, del 16 de septiembre de 2003, se constituyó con carácter permanente la Comisión de Implementación y Seguimiento de la Reestructuración Judicial del Poder Judicial (CISJ). Empero con el tiempo desapareció en los hechos o en todo caso le concernían a los órganos de gobierno judicial las tareas propias de modernización y reactualización judicial, con la asistencia de comisiones institucionales por especialidad - transitorias o por producto terminado - integradas por jueces, en materia de carrera judicial, civil, penal, casación, entre otras; con una participación modesta del Centro de Investigaciones Judiciales en estos años, pues entró en proceso de recuperación institucional tras su suspensión en la década de los noventa, corrían los años 2004 al 2006.

Desde el 2007, las tareas de reforma y modernización al interior de la rama judicial, de acuerdo con el marco legal vigente, continuarán a cargo de una estructura triple de organización y toma de decisiones: 
la Presidencia del Poder Judicial, la Sala Plena de la Corte Suprema de Justicia y el Consejo Ejecutivo del Poder Judicial ${ }^{12}$, además de contar con el apoyo de las comisiones institucionales de jueces de carácter temporal para determinados temas en concreto, en estas convergerán las diferentes comisiones, equipos, unidades y órganos permanentes por especialidad de la organización administrativa directamente relacionadas con la renovación de la judicatura. Aquí entra a tallar el Centro de Investigaciones Judiciales reasumiendo dos temas fundamentales dentro de todo proceso de reforma de la impartición de justicia: la capacitación judicial y la predictibilidad de las decisiones jurisdiccionales. En el primer caso, el tratamiento orgánico y permanente en la organización de actividades de capacitación y certámenes institucionales de jueces de todos los niveles y a escala nacional; y en cuanto al segundo punto, a través de la realización de los plenos jurisdiccionales y la sistematización electrónica de la jurisprudencia; además de avocarse a determinados proyectos e integrando comisiones dedicadas a temas específicos de la problemática judicial y las publicaciones editoriales.

Es notorio el cambio morfológico sustantivo del Centro de Investigaciones Judiciales desde su creación hasta nuestros días. Antes de la vigencia de la Ley Orgánica del Poder Judicial, en 1992 (Decreto Legislativo n. 767 de 1991, Ley n. ${ }^{\circ} 25869$ y luego su Texto Único Ordenado de 1993), era un órgano dependiente de la Corte Suprema de Justicia bajo la conducción de un Consejo de Gobierno presidido por el presidente de dicho poder estatal, con un vicepresidente ejecutivo a cargo del vocal en lo administrativo de la Corte Suprema, e integrado por magistrados en actividad y cesantes y representantes de la Federación Nacional de Colegios de Abogados

12 En algún momento se barajaba una propuesta - no concretada- de creación de un órgano denominado Dirección General de la Reestructuración Judicial, con una unidad responsable en cada distrito judicial. Ver Poder Judicial del Perú (2007, p. 9). 
y del sistema de la universidad peruana. A partir del actual siglo de vigencia formal y material del Centro de Investigaciones Judiciales, este se configura como un órgano de apoyo dependiente del Consejo Ejecutivo del Poder Judicial, órgano de gobierno y decisorio, a cargo de un director no magistrado, con un Consejo Consultivo integrado por jueces de todos los niveles y presidido por un juez supremo consejero.

Entretando, dentro de esta atmósfera de reformulación de la justicia, fuera del Poder Judicial, en junio de 2003 se constituyeron los grupos de trabajo del programa de acciones inmediatas del Plan de Modernización y Reorganización del Ministerio Público mediante la Resolución n. ${ }^{\circ}$ 847-2003-MP, y en diciembre el Congreso de la República expidió la Ley n. ${ }^{\circ} 28149$, que regula la participación de la sociedad en los órganos de control del Poder Judicial y del Ministerio Público. En octubre de 2004 se instaló la Comisión Especial de Estudio del Plan Nacional de Reforma Integral de la Administración de Justicia del Congreso de la República, cuyo propósito fue el estudio, sistematización y difusión del Plan Nacional de Reforma Integral de la Administración de Justicia de la CERIAJUS, así como coordinar y apoyar su implementación. Por su parte, el Ministerio de Justicia creó dos comisiones especiales para impulsar también la implementación del citado plan, una en septiembre de 2004 y la otra en agosto de 2005.

\subsubsection{Segundo momento estelar}

Ahora bien, entrando a la hora presente o «segundo escenario estelar», la reforma política y judicial es una respuesta natural de la prolongada crisis política, desde septiembre de 2017, y la crisis del sistema de justicia, desde julio de 2018, lo que obligó al Estado peruano en su conjunto a plantearse la necesidad de hacer cambios estructurales y transformaciones institucionales. Algo tenía que hacerse. En efecto, se respiraba una crisis política inusitada cuyo 
punto fulminante fue la disolución del pleno del Congreso de la República el 30 de septiembre de 2019, como resultado del triángulo de la fatalidad: cuestión de confianza, disolución parlamentaria y vacancia presidencial. Se descubrió también una enorme crisis que sacudió los cimientos del sistema de justicia y del aparato judicial, con los CNM audios de la corrupción. Nueva época de tratamiento y solución a la crisis del sistema de justicia que vislumbra dos subetapas (Domínguez, 2019, pp. 369-370):

a) La iniciada en la segunda mitad del 2018, por la Comisión Consultiva denominada Comisión de Reforma del Sistema de Justicia, dependiente de la Presidencia de la República y sin participación del Poder Judicial (Resolución Suprema n. ${ }^{\circ} 142$ 2018-PCM del 12 de julio), que elaboró el informe «Hacia un sistema de justicia honesto y eficiente», acompañado de anexos con siete proyectos normativos: proyecto de ley de reforma constitucional del Consejo Nacional de la Magistratura, proyectos de leyes de creación del Consejo para la Reforma del Sistema de Justicia, la Autoridad Nacional de Integridad y Control en el Poder Judicial y en el Ministerio Público, la Fiscalía Suprema Anticorrupción, de modificación del TUO del proceso contencioso administrativo, la incorporación del título VI «Transparencia en el Sistema de Justicia» al TUO de la Ley de Transparencia y Acceso a la Información Pública, y el proyecto para incentivar la probidad en el ejercicio de la abogacía.

Igualmente, este espacio de tiempo comprende la iniciativa de la Sala Plena de la Corte Suprema de Justicia a través del Plan de Cambios Urgentes del Poder Judicial, del 26 de julio, y los aportes de sus seis comisiones temáticas, como son las Comisiones de Integridad y Control Institucional, para la Reformulación de las Prácticas y Competencias Casatorias de la Corte Suprema, para la Reforma Estructural, Orgánica y Operativa del Consejo Nacional 
de la Magistratura y la Academia de la Magistratura, para la Adaptación Estratégica de los Procedimientos y Competencias en lo Contencioso Administrativo, para la Democratización y Transparencia de la Elección para Nuevas Autoridades Judiciales, y Comisión para la Modernización Tecnológica y de los Procesos de Optimización del Servicio Judicial (Acuerdo n. ${ }^{\circ}$ 32-2018 de la Décimo Segunda Sesión Extraordinaria de la Sala Plena de la Corte Suprema de Justicia), que contó con el concurso de la Gerencia General, el Gabinete Técnico de Asesores de la Presidencia del Poder Judicial, el Centro de Investigaciones Judiciales y demás dependencias al interior de la judicatura. Previamente, el Poder Judicial había sido declarado en emergencia por noventa días, prorrogados posteriormente (Resolución Administrativa n. ${ }^{\circ}$ 203-2018-CE-PJ del 16 de julio), como también la declaración de emergencia funcional del Consejo Ejecutivo del Poder Judicial (Resolución Administrativa n. ${ }^{\circ}$ 12-2018-SP-CS-PJ del 20 de agosto).

Esta fase comprende, además - a nivel legislativo-, la dación de la Ley n. ${ }^{\circ}$ 30833, Ley que declara en situación de emergencia el Consejo Nacional de la Magistratura y suspende su Ley Orgánica (Diario Oficial El Peruano del 28 de julio de 2018). Se cierra este breve espacio con la aprobación de tres de las cuatro reformas constitucionales propuestas por el Gobierno a la ciudadanía vía referéndum del 9 de diciembre, una de ellas sobre la nueva conformación y funciones de la Junta Nacional de Justicia (el $86 \%$ de los votantes dijo «sí» a esta reforma). Vale decir, se opta por una solución conocida, un órgano externo con sus propios matices ante un problema también conocido, la corrupción manifiesta imperante; haciéndonos recordar el proyecto sobre la creación de un Consejo Nacional de Justicia en 1931, que también tuvo su origen en los actos de corrupción de esa época. 
b) Su continuación en el 2019, en tanto el proceso de reforma será a través de una especie de comité de crisis al más alto nivel, un gran centro de política pública en justicia, un ente de coordinación y seguimiento de las políticas públicas en materia de justicia denominado Consejo para la Reforma del Sistema de Justicia, creado por la Ley n. 30942 (Diario Oficial El Peruano del 8 de mayo) y conformado por los titulares de los poderes representativos: presidente de la República, presidente del Congreso de la República, presidente del Poder Judicial, presidente del Tribunal Constitucional, fiscal de la Nación, presidente de la Junta Nacional de Justicia, contralor general de la República y defensor del pueblo. Esfuerzo que deberá plasmarse en un documento de trabajo sobre políticas públicas y medidas en materia de justicia, y se espera con bastante atención. Este espacio interinstitucional tiene en su Consejo Técnico para la Reforma del Sistema de Justicia y su Secretaría Técnica, los órganos de apoyo y asesoría para tan ambiciosa labor.

En ese tono reformista descrito, a la pregunta quién nombra y quién controla, la respuesta ha sido la aprobación de la ley de reforma constitucional sobre un tema peliagudo y sensible como es la elección de los jueces y fiscales, y dos leyes que modifican de manera radical el Texto Único Ordenado de la Ley Orgánica del Poder Judicial, la Ley Orgánica del Ministerio Público y la Ley de la Carrera Judicial sobre los órganos del control del aparato judicial y fiscal. Con ello se tiene la siguiente plataforma normativa vigente: Ley n. ${ }^{\circ}$ 30904, Ley de reforma constitucional sobre la conformación y funciones de la Junta Nacional de Justicia (Diario Oficial El Peruano del 10 de enero de 2019) ${ }^{13}$, Ley n. ${ }^{\circ}$ 30916, Ley Orgánica

13 Sobre la Junta Nacional de Justicia podemos anotar provisoriamente que la opción constitucional aprobada ratifica, con sus propios rasgos funcionales, un modelo que tiene algunos matices o instituciones de la fórmula europea y del estilo norteamericano sobre sistema de gobierno y de organización judicial, como suele 
de la Junta Nacional de Justicia (Diario Oficial El Peruano del 19 de febrero de 2019), Ley n. ${ }^{\circ} 30943$, Ley de Creación de la Autoridad Nacional de Control del Poder Judicial ${ }^{14}$, y Ley n. ${ }^{0} 30944$, Ley de Creación de la Autoridad Nacional de Control del Ministerio Público (Diario Oficial El Peruano del 8 de mayo de 2019 para ambas), que ciertamente han generado comentarios y pareceres de distinto calado. Especial tesitura que da inicio a la formulación conjunta de los criterios para la elaboración de la política pública nacional en materia de justicia a cargo de los poderes estatales integrantes del Consejo para la Reforma del Sistema de Justicia.

Este complicado quehacer ha sido puesto en marcha también por el propio Poder Judicial, al disponer la elaboración de las líneas rectoras y propuestas de políticas públicas en materia de justicia divididas en siete ejes temáticos: independencia e imparcialidad judicial, selección y nombramiento de jueces, formación y capacitación del magistrado, sistema disciplinario, interoperabilidad en el sistema de justicia, sostenibilidad económica y presupuestaria, y acceso a la justicia y carga procesal (Resolución n. ${ }^{\circ}$ 328-2019-P-PJ del 13 de junio); que han sido recogidos en el documento titulado «Políticas públicas del Poder Judicial para la Reforma del Sistema de Justicia (en el contexto de la Ley n. ${ }^{\circ}$ 30942)», presentado en el mes de agosto de 2019 al Consejo para la Reforma del Sistema de Justicia.

A fines del año pasado el Poder Judicial ha concluido la elaboración de su Plan Estratégico Institucional para el período 2020-2030, y de aprobarse se constituirá en el primer instrumento

suceder en América Latina ante las numerosas variantes de los denominados habitualmente Consejos de la Magistratura o de la Judicatura, acaso un «modelo» latinoamericano.

$14 \mathrm{Al}$ erigirse un órgano de control desde «afuera» de la judicatura se tiene un peculiar modelo en reemplazo del modelo cuasicerrado y luego mixto de participación de la sociedad civil en el Órgano de Control de la Magistratura. 
de gestión pública que reúna el pensamiento estratégico judicial para una década desde un enfoque democrático (un segundo intento - coincidentemente- después de diez años también), una especie de hoja de ruta con líneas estratégicas, acciones y metas de política pública claramente identificadas y medibles, en armonía con los proyectos que presentará el Consejo para la Reforma de la Justicia. El plan referido pretende «contribuir a la construcción de una sociedad más pacífica, donde prime el respeto a la libertad, a la democracia [cursivas añadidas], a la Constitución y al Estado de derecho $[\ldots] \rrbracket^{15}$. Para las acciones antes descritas, los órganos de gobierno judicial cuentan con los siguientes enlaces del Poder Judicial: Gabinete Técnico de Asesores de la Presidencia del Poder Judicial para los temas vinculados a la Junta Nacional de Justicia, Gerencia General para el Plan Estratégico Institucional 2020-2030 y el Centro de Investigaciones Judiciales como enlace técnico ante el Consejo para la Reforma del Sistema de Justicia.

En cuanto al órgano fiscal, mediante Resolución de la Fiscalía de la Nación se declaró en emergencia el Ministerio Público por un plazo de sesenta días (n. ${ }^{\circ} 401-2019-M P F N$ del 26 de febrero), se conformaron equipos de trabajo al interior del Ministerio Público para la elaboración de las líneas rectoras y propuestas de políticas públicas en temas de justicia sobre la base de seis ejes: autonomía e independencia fiscal, selección y nombramiento de fiscales, formación y capacitación, sostenibilidad económica y presupuesto, interoperabilidad y acceso a la justicia y descarga procesal (Resolución n. ${ }^{\circ}$ 1772-2019-MP-FN del 15 de julio).

15 Así lo ha señalado el presidente del Poder Judicial Dr. José Luis Lecaros Cornejo en una corta entrevista sobre el plan y que contó en su formulación con la Universidad Esan como facilitadora. Ver Diario Oficial El Peruano. Lima, 4 de enero de 2020, p. 7. Como antecedente se tiene el proyecto «Bases para el Plan Decenal de Modernización del Poder Judicial 2008-2017», a iniciativa del presidente del Poder Judicial de ese entonces, Dr. Francisco Artemio Távara Córdova (2007-2008). 


\subsection{De tiempo en tiempo: haciendo y deshaciendo comisiones}

Si se toma como punto de partida la segunda mitad del siglo XX, más concretamente, el año 1958 antes referido, han transcurrido un poco más de sesenta años desde la creación de una primera comisión con el objeto de liderar y procurar reordenar el sistema de justicia o judicial. La historia de su reforma a través de las comisiones para tal fin se condensa en el cuadro siguiente:

Organismos y comisiones creados especialmente para el proceso de reforma

\begin{tabular}{|c|c|c|c|c|}
\hline N. ${ }^{\circ}$ & Ley & Nombre & Conformación & Características \\
\hline 1 & $\begin{array}{l}1958 \\
\text { Ley } \\
\text { n. }{ }^{\circ} 13036\end{array}$ & $\begin{array}{l}\text { Comisión } \\
\text { encargada de } \\
\text { estudiar la } \\
\text { reforma del } \\
\text { Poder Judicial }\end{array}$ & $\begin{array}{l}\text { - Delegado del Poder Ejecutivo, } \\
\text { designado por el presidente } \\
\text { de la República } \\
\text { - Un senador } \\
\text { - Un diputado } \\
\text { - Un magistrado de la Corte } \\
\text { Suprema } \\
\text { - Decanos de cada una de las } \\
\text { Facultades de Derecho de } \\
\text { universidades públicas } \\
\text { - Decano del Colegio de } \\
\text { Abogados de Lima } \\
\text { - Presidente de la Federación } \\
\text { de Colegios de Abogados del } \\
\text { Perú }\end{array}$ & $\begin{array}{l}\text { Comisión } \\
\text { interinstitucional } \\
\text { temporal, } \\
\text { integrada por } \\
\text { representantes de } \\
\text { cada institución } \\
\text { y encargada } \\
\text { de formular el } \\
\text { anteproyecto } \\
\text { normativo } \\
\text { correspondiente }\end{array}$ \\
\hline 2 & $\begin{array}{l}1975 \\
\text { Decreto } \\
\text { Ley } \\
\text { n. }{ }^{\text {o } 21307}\end{array}$ & $\begin{array}{l}\text { Comisión de } \\
\text { Reforma Judicial }\end{array}$ & $\begin{array}{l}\text { - Presidente de la Corte } \\
\text { Suprema de Justicia de la } \\
\text { República, quien lo preside } \\
\text { - Tres vocales de la misma } \\
\text { Corte } \\
\text { - Un vocal de Corte Superior } \\
\text { - Un magistrado de primera } \\
\text { instancia }\end{array}$ & $\begin{array}{l}\text { Comisión } \\
\text { institucional } \\
\text { (interna) y } \\
\text { designados } \\
\text { por el Poder } \\
\text { Ejecutivo, salvo el } \\
\text { presidente de la } \\
\text { Corte Suprema }\end{array}$ \\
\hline
\end{tabular}




\begin{tabular}{|c|c|c|c|c|}
\hline 3 & $\begin{array}{l}1979 \\
\text { D. L. } \\
\text { n. } 22422\end{array}$ & $\begin{array}{l}\text { Centro de } \\
\text { Investigaciones } \\
\text { Judiciales (CDIJ) } \\
\text { Luego con un } \\
\text { nuevo formato } \\
\text { orgánico- } \\
\text { funcional el } \\
\text { Centro de } \\
\text { Investigaciones } \\
\text { Judiciales (CIJ), } \\
\text { de acuerdo con } \\
\text { el TUO de la Ley } \\
\text { Orgánica del } \\
\text { Poder Judicial, } \\
\text { iniciará sus } \\
\text { funciones en la } \\
\text { práctica en el } \\
\text { siglo XXI }\end{array}$ & $\begin{array}{l}\text { - Presidente de la Corte } \\
\text { Suprema, quien lo preside } \\
\text { - Un vocal en lo } \\
\text { administrativo de la Corte } \\
\text { Suprema } \\
\text { - Dos vocales de la Corte } \\
\text { Suprema } \\
\text { - Un magistrado de Corte } \\
\text { Superior } \\
\text { - Un magistrado de primera } \\
\text { instancia } \\
\text { - Dos magistrados cesantes o } \\
\text { jubilados del Poder Judicial } \\
\text { - Un representante de la } \\
\text { Federación Nacional de } \\
\text { Colegios de Abogados } \\
\text { - Un representante del Sistema } \\
\text { de la Universidad Peruana }\end{array}$ & $\begin{array}{l}\text { Órgano } \\
\text { institucional } \\
\text { permanente } \\
\text { con cierta } \\
\text { participación de } \\
\text { la sociedad civil. } \\
\text { El CDIJ estuvo } \\
\text { vigente toda la } \\
\text { década de los } \\
\text { ochenta. } \\
\text { El reformulado } \\
\text { CIJ sigue en la } \\
\text { actualidad }\end{array}$ \\
\hline 4 & 1992 & $\begin{array}{l}\text { Comisión de } \\
\text { Reestructuración } \\
\text { de la } \\
\text { Administración } \\
\text { de Justicia }\end{array}$ & $\begin{array}{l}\text { - Ministro de Justicia, quien lo } \\
\text { preside } \\
\text { - Académicos del derecho } \\
\text { - Exjueces } \\
\text { Posteriormente se integran: } \\
\text { - Representantes de los demás } \\
\text { poderes del Estado } \\
\text { - Representante del Colegio de } \\
\text { Abogados de Lima } \\
\text { - Magistrados } \\
\text { - Juristas } \\
\text { - Representantes de } \\
\text { instituciones de } \\
\text { investigación }\end{array}$ & $\begin{array}{l}\text { Comisión } \\
\text { temporal } \\
\text { inicialmente } \\
\text { del Poder } \\
\text { Ejecutivo y luego } \\
\text { interinstitucional } \\
\text { y con el concurso } \\
\text { de otras } \\
\text { dependencias no } \\
\text { estatales }\end{array}$ \\
\hline 5 & $\begin{array}{l}1995 \\
\text { Ley } \\
\text { n. } 26546\end{array}$ & $\begin{array}{l}\text { Comisión } \\
\text { Ejecutiva del } \\
\text { Poder Judicial }\end{array}$ & $\begin{array}{l}\text { - Presidente de la Corte } \\
\text { Suprema, quien lo preside } \\
\text { - Vocal supremo presidente de } \\
\text { la Sala Penal Permanente } \\
\text { - Vocal supremo presidente } \\
\text { de la Sala Constitucional y } \\
\text { Social Permanente }\end{array}$ & $\begin{array}{l}\text { Órgano de } \\
\text { gobierno judicial } \\
\text { transitorio } \\
\text { y asumió las } \\
\text { labores de } \\
\text { reforma judicial, } \\
\text { contaba con un } \\
\text { secretario técnico } \\
\text { (titular de pliego) }\end{array}$ \\
\hline
\end{tabular}




\begin{tabular}{|c|c|c|c|c|}
\hline 6 & $\begin{array}{l}1996 \\
\text { Ley } \\
\text { n. }{ }^{\circ} 26623\end{array}$ & $\begin{array}{l}\text { Consejo de } \\
\text { Coordinación } \\
\text { Judicial }\end{array}$ & $\begin{array}{l}\text { - Presidente de la Corte } \\
\text { Suprema de Justicia, quien } \\
\text { lo preside } \\
\text { - Presidente del Tribunal } \\
\text { Constitucional } \\
\text { - Ministro de Justicia } \\
\text { - Presidente del Consejo } \\
\text { Nacional de la Magistratura } \\
\text { - Fiscal de la Nación } \\
\text { - Presidente del Consejo } \\
\text { Directivo de la Academia de } \\
\text { la Magistratura } \\
\text { - Decano del Colegio de } \\
\text { Abogados de Lima } \\
\text { - Presidente de la Junta de } \\
\text { Decanos de los Colegios de } \\
\text { Notarios del Perú } \\
\text { - Un representante de las } \\
\text { Facultades de Derecho de las } \\
\text { universidades nacionales } \\
\text { - Un representante de las } \\
\text { Facultades de Derecho de las } \\
\text { universidades particulares }\end{array}$ & $\begin{array}{l}\text { Comisión } \\
\text { interinstitucional } \\
\text { conformada por } \\
\text { representantes de } \\
\text { cada institución, } \\
\text { en la práctica } \\
\text { no funcionó. El } \\
\text { protagonismo } \\
\text { estuvo a cargo de } \\
\text { las Comisiones } \\
\text { Ejecutivas del } \\
\text { Poder Judicial y } \\
\text { del Ministerio } \\
\text { Público } \\
\text { (primera } \\
\text { disposición } \\
\text { transitoria de la } \\
\text { ley de creación) }\end{array}$ \\
\hline 7 & $\begin{array}{l}2001 \\
\text { Convenio } \\
\text { de Coo- } \\
\text { peración } \\
\text { Interins- } \\
\text { titucional } \\
\text { y Adenda }\end{array}$ & $\begin{array}{l}\text { Grupo de Trabajo } \\
\text { de Alto Nivel } \\
\text { (GTAN) para la } \\
\text { Modernización } \\
\text { del Sistema } \\
\text { Nacional de } \\
\text { Administración } \\
\text { de Justicia (SNAJ) }\end{array}$ & $\begin{array}{l}\text { - Presidente del Poder Judicial, } \\
\text { quien lo preside } \\
\text { - Presidente del Tribunal } \\
\text { Constitucional } \\
\text { - Fiscal de la Nación } \\
\text { - Presidente del Consejo } \\
\text { Nacional de la Magistratura } \\
\text { - Presidente del Consejo } \\
\text { Directivo de la Academia de } \\
\text { la Magistratura } \\
\text { - Ministro de Justicia }\end{array}$ & $\begin{array}{l}\text { Grupo } \\
\text { interinstitucional } \\
\text { integrado por los } \\
\text { representantes de } \\
\text { cada institución }\end{array}$ \\
\hline 8 & $\begin{array}{l}2003 \\
\text { Ley } \\
\text { n. }{ }^{\circ} 28083\end{array}$ & $\begin{array}{l}\text { Comisión } \\
\text { Especial para } \\
\text { la Reforma } \\
\text { Integral de la } \\
\text { Administración } \\
\text { de Justicia } \\
\text { (CERIAJUS) }\end{array}$ & $\begin{array}{l}\text { - Presidente del Poder Judicial, } \\
\text { quien lo preside } \\
\text { - Fiscal de la Nación } \\
\text { - Presidente del Consejo } \\
\text { Nacional de la Magistratura } \\
\text { - Un representante del } \\
\text { Tribunal Constitucional }\end{array}$ & $\begin{array}{l}\text { Comisión } \\
\text { interinstitucional } \\
\text { temporal, } \\
\text { conformada por } \\
\text { los titulares y } \\
\text { representantes de } \\
\text { las instituciones } \\
\text { involucradas }\end{array}$ \\
\hline
\end{tabular}




\begin{tabular}{|c|c|c|c|c|}
\hline & & & $\begin{array}{l}\text { - Presidente del Consejo } \\
\text { Directivo de la Academia de la } \\
\text { Magistratura } \\
\text { - Ministro de Justicia } \\
\text { - Defensor del pueblo } \\
\text { - Dos representantes de la } \\
\text { Comisión de Justicia y } \\
\text { Derechos Humanos del } \\
\text { Congreso de la República } \\
\text { - Cinco miembros elegidos por } \\
\text { las instituciones de la sociedad } \\
\text { civil participantes en el Foro } \\
\text { del Acuerdo Nacional }\end{array}$ & \\
\hline 9 & $\begin{array}{l}2003 \\
\text { Reso- } \\
\text { lución } \\
\text { n. }{ }^{\circ} 191- \\
2003-\mathrm{P}-\mathrm{PJ}\end{array}$ & $\begin{array}{l}\text { Acuerdo Nacional } \\
\text { por la Justicia } \\
\text { Para la } \\
\text { elaboración de } \\
\text { las propuestas } \\
\text { de políticas de } \\
\text { Estado del Poder } \\
\text { Judicial contó } \\
\text { con el informe de } \\
\text { la Comisión de } \\
\text { Reestructuración } \\
\text { del Poder Judicial } \\
\text { conformado } \\
\text { por jueces de } \\
\text { todos los niveles } \\
\text { (Resolución n. } \\
\text { 035-2003-P-PJ) }\end{array}$ & $\begin{array}{l}\text { Conducido por un Grupo } \\
\text { Impulsor conformado } \\
\text { por cinco personalidades } \\
\text { convocadas por el Poder } \\
\text { Judicial }\end{array}$ & $\begin{array}{l}\text { Programa } \\
\text { temporal } \\
\text { auspiciado por la } \\
\text { Presidencia del } \\
\text { Poder Judicial } \\
\text { e integrado por } \\
\text { personalidades } \\
\text { externas a este } \\
\text { poder del Estado }\end{array}$ \\
\hline 10 & $\begin{array}{l}2016 \\
\text { Decla- } \\
\text { ración } \\
\text { conjunta, } \\
\text { acta de } \\
\text { creación }\end{array}$ & $\begin{array}{l}\text { Acuerdo } \\
\text { Nacional por la } \\
\text { Justicia }\end{array}$ & $\begin{array}{l}\text { - Presidente del Poder Judicial } \\
\text { - Fiscal de la Nación } \\
\text { - Presidente del Consejo } \\
\text { Nacional de la Magistratura } \\
\text { - Presidente de la Academia } \\
\text { de la Magistratura } \\
\text { - Ministro de Justicia }\end{array}$ & $\begin{array}{l}\text { Mecanismo de } \\
\text { coordinación } \\
\text { interinstitucional } \\
\text { integrado por } \\
\text { los titulares de } \\
\text { cada institución. } \\
\text { El Tribunal } \\
\text { Constitucional } \\
\text { decidió no } \\
\text { participar desde } \\
\text { la creación del } \\
\text { Acuerdo }\end{array}$ \\
\hline
\end{tabular}




\begin{tabular}{|c|c|c|c|c|}
\hline 11 & $\begin{array}{l}2018 \\
\text { Reso- } \\
\text { lución } \\
\text { Suprema } \\
\text { n. }{ }^{\circ} 142- \\
2018- \\
\text { PCM }\end{array}$ & $\begin{array}{l}\text { Comisión } \\
\text { de Reforma } \\
\text { del Sistema } \\
\text { de Justicia } \\
\text { (Comisión } \\
\text { Consultiva) }\end{array}$ & $\begin{array}{l}\text { Presidido por un diplomático } \\
\text { e integrado por seis abogados } \\
\text { convocados por el presidente } \\
\text { de la República (siete } \\
\text { profesionales en total) }\end{array}$ & $\begin{array}{l}\text { Comisión } \\
\text { dependiente } \\
\text { del presidente } \\
\text { de la República } \\
\text { integrada por } \\
\text { profesionales } \\
\text { externos al } \\
\text { Ejecutivo. } \\
\text { Comisión } \\
\text { express, de } \\
\text { corta duración, } \\
\text { reemplazada } \\
\text { por el Consejo } \\
\text { para la Reforma } \\
\text { del Sistema de } \\
\text { Justicia }\end{array}$ \\
\hline 12 & $\begin{array}{l}2019 \\
\text { Ley } \\
\text { n. }{ }^{\circ} 30942\end{array}$ & $\begin{array}{l}\text { Consejo para } \\
\text { la Reforma } \\
\text { del Sistema de } \\
\text { Justicia }\end{array}$ & $\begin{array}{l}\text { - Presidente de la República, } \\
\text { quien lo preside por un año } \\
\text { - Presidente del Congreso de } \\
\text { la República } \\
\text { - Presidente del Poder Judicial } \\
\text { - Presidente del Tribunal } \\
\text { Constitucional } \\
\text { - Fiscal de la Nación } \\
\text { - Presidente de la Junta } \\
\text { Nacional de Justicia } \\
\text { - Contralor general de la } \\
\text { República } \\
\text { - Defensor del pueblo }\end{array}$ & $\begin{array}{l}\text { Espacio } \\
\text { interinstitucional } \\
\text { de naturaleza } \\
\text { permanente, } \\
\text { integrado por los } \\
\text { titulares de cada } \\
\text { institución. La } \\
\text { presidencia es } \\
\text { rotativa. } \\
\text { Actualmente } \\
\text { vigente }\end{array}$ \\
\hline
\end{tabular}

Al analizar este cuadro en concordancia con el carácter cíclico de la reforma de justicia anteriormente revisado, el lector podrá darse cuenta de la existencia de una variedad de comisiones - con distintos nombres - a escala institucional e interinstitucional. Vale decir, comisiones al interior de cada uno de los órganos o poderes públicos en terreno de la justicia, con su particular visión, y aquellas con la participación plural y conjunta de diferentes estamentos del sistema de justicia, la comunidad jurídica y de la sociedad según corresponda. 
El fenómeno de la «comisionitis» no solo se ha dado dentro de cada institución, como afirma Javier de Belaunde (2006, p. 181), también la historia nos revela otra suerte de comisionitis sectorial o fuera de las cuatro paredes del Palacio de Justicia, iniciada con la comisión de fines de los cincuenta. En seis décadas se ha tenido aproximadamente doce comisiones, consejos, centros, acuerdos o grupos - como se quiera llamar- considerados dentro del cuadro sugerido por el papel relevante en el desarrollo de la reforma. Siete de vocación interinstitucional y cinco institucionales (1975, 1979, 1995, 2003 - Acuerdo Nacional por la Justicia- y 2018).

Este paisaje, evidentemente, demuestra los altibajos, vaivenes y embates de nuestro devenir republicano, ante la complejidad de la problemática de la justicia y las relaciones políticas en cada proceso gubernativo; situación que genera en más de un especialista preguntas como las siguientes: ¿es posible reformar la justicia?, ¿la reforma es imposible?, ¿reforma siempre pendiente?, ¿hay esperanza? ${ }^{16}$, o $¿$ debemos confiar en este nuevo Consejo para la Reforma del Sistema de Justicia?

De lo vertido anteriormente, complementan la labor de cambios, la presencia de otros organismos o espacios de coordinación de grado nacional. Un viejo conocido, otro en desarrollo y uno nuevo por conocer deben concurrir para el éxito del Consejo para la Reforma del Sistema de Justicia, y son, por orden cronológico, el Acuerdo Nacional, la Comisión de Alto Nivel Anticorrupción ${ }^{17}$

16 Linn Hammergren (2007), Luis Pásara $(2008,2014$, 2019) y la participación de Raúl Ferrero Costa (2003) en la mesa redonda sobre la reforma del Poder Judicial, al señalar que la reforma judicial es siempre un tema pendiente en la agenda por problemas endémicos.

17 Antes de esta comisión, han pasado otras experiencias ya sea desde el Ministerio de Justicia o desde el Consejo de Ministros: Programa Nacional de Anticorrupción, Comisión Nacional de Lucha contra la Corrupción y la Promoción de la Ética y Transparencia en la Gestión Pública y en la Sociedad, Consejo Nacional Anticorrupción y la Oficina Nacional Anticorrupción. 
y la Junta Nacional de Justicia (órgano constitucional). Si bien coincidentemente no han sido nada fáciles y cómodos sus procesos de formación, han pasado por diferentes vallas de todo tipo y situaciones coyunturales, como ha ocurrido en la elección de los integrantes de la Junta Nacional de Justicia. Se espera superar las tensiones por lo que se viene: una ardua y complicada labor para la Junta Nacional de Justicia en temas pendientes sobre reexamen de los procesos de selección profesional y ratificación de años anteriores, pedidos de destitución de magistrados (84 casos a diciembre de 2019) y aproximadamente 2871 magistrados para los procesos de ratificación ${ }^{18}$.

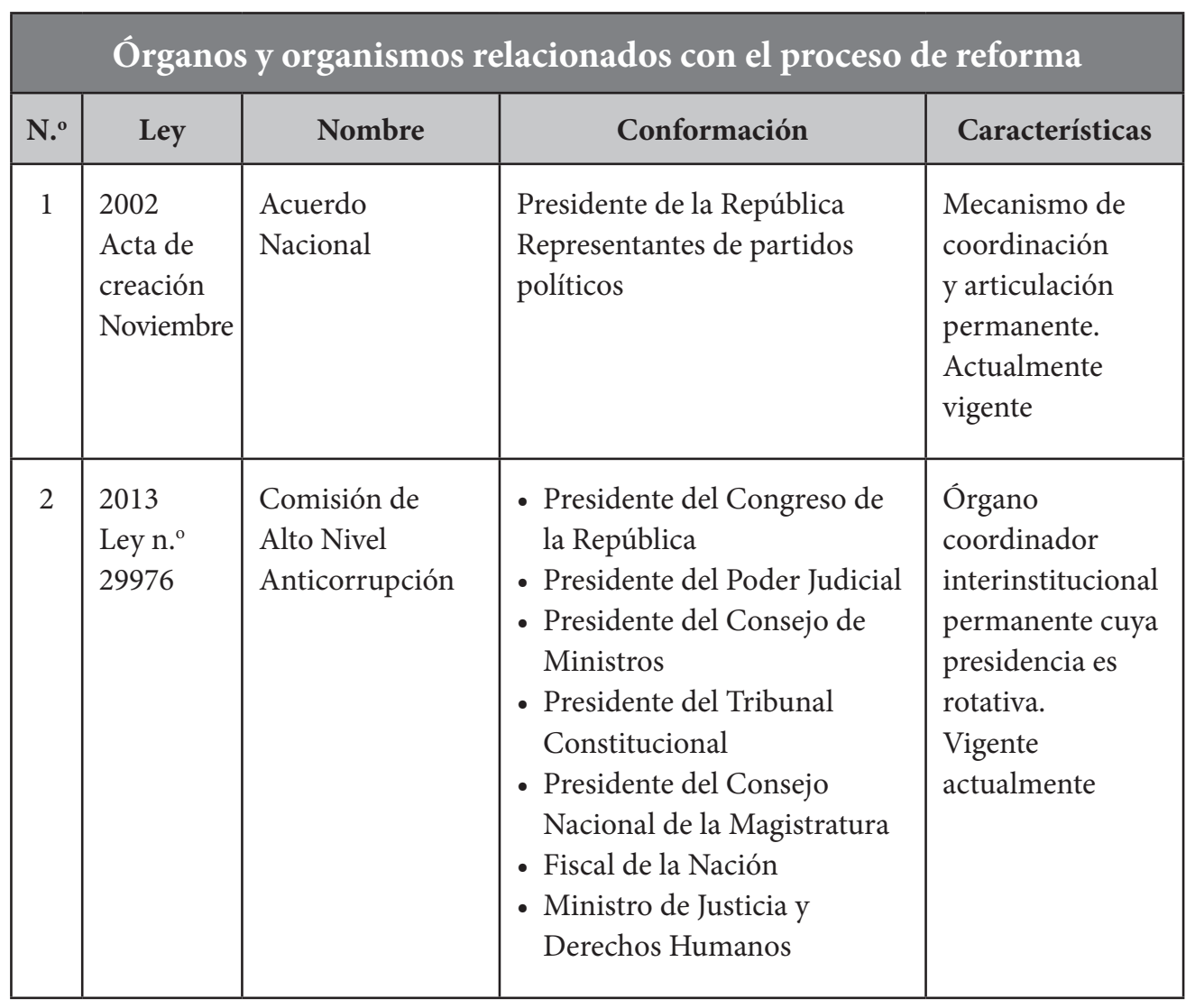

18 Datos extraídos del Diario Oficial El Peruano. Lima, 31 de diciembre de 2019, p. 5. 


\begin{tabular}{|c|c|c|c|c|}
\hline & & & $\begin{array}{l}\text { - Presidente de la Asamblea } \\
\text { Nacional de Gobiernos } \\
\text { Regionales } \\
\text { - Presidente de la Asociación } \\
\text { de Municipalidades del Perú } \\
\text { - Secretario ejecutivo del Foro } \\
\text { del Acuerdo Nacional } \\
\text { - Coordinador general de } \\
\text { la Comisión de Alto Nivel } \\
\text { Anticorrupción }\end{array}$ & \\
\hline 3 & $\begin{array}{l}2019 \\
\text { Ley n. }^{\circ} \\
30904, \\
\text { Ley de } \\
\text { Reforma } \\
\text { Constitu- } \\
\text { cional }\end{array}$ & $\begin{array}{l}\text { Junta Nacional de } \\
\text { Justicia }\end{array}$ & $\begin{array}{l}\text { - Siete integrantes elegidos } \\
\text { mediante concurso público } \\
\text { de méritos } \\
\text { La Comisión Especial } \\
\text { encargada del concurso está } \\
\text { conformada por: } \\
\text { - Defensor del pueblo, quien } \\
\text { la preside } \\
\text { - Presidente del Poder Judicial } \\
\text { - Fiscal de la Nación } \\
\text { - Presidente del Tribunal } \\
\text { Constitucional } \\
\text { - Contralor general de la } \\
\text { República } \\
\text { - Un rector elegido en } \\
\text { votación por los rectores } \\
\text { de las universidades } \\
\text { públicas licenciadas con } \\
\text { más de cincuenta años de } \\
\text { antigüedad } \\
\text { - Un rector elegido en } \\
\text { votación por los rectores } \\
\text { de las universidades } \\
\text { privadas licenciadas con } \\
\text { más de cincuenta años de } \\
\text { antigüedad. }\end{array}$ & $\begin{array}{l}\text { Órgano } \\
\text { constitucional } \\
\text { permanente, } \\
\text { sus integrantes } \\
\text { son elegidos por } \\
\text { cinco años sin } \\
\text { reelección }\end{array}$ \\
\hline
\end{tabular}




\section{ALGUNAS REFLEXIONES EN TORNO AL PROCESO DE REFORMA DE LA JUSTICIA}

Ante las válidas preocupaciones sobre si es posible reformar el sistema de justicia o en cuestiones de cambios hay algún indicio de esperanza, desde un análisis comparado de los intentos reformistas y las diversas comisiones aludidas, tratando de alinear una proceso viable y optimista de refundación de la justicia se puede identificar ciertas notas características del actual Consejo para la Reforma del Sistema de Justicia. Además de la participación directa del presidente de la República, la vocación de permanencia en el tiempo de un ente corporativo central para la cooperación, articulación (o rearticulación si cabe el término) y seguimiento de la implementación y ejecución de las políticas públicas consensuadas y los respectivos procesos de reforma de los estamentos integrantes del citado Consejo (donde la interoperabilidad y transversalidad caen de maduras); no es otra cosa que evidenciar y asegurar que las políticas públicas y las acciones planteadas deban tener el efecto deseado dentro del sistema y en la sociedad. «En esa línea, se busca contar con un mecanismo de alto nivel para la coordinación de los esfuerzos de la reforma judicial. Con ello, se busca asegurar el impulso y la ejecución de las decisiones adoptadas con miras a la mejora de la administración de justicia en nuestro país» (Asociación Civil Transparencia, 2018, p. 27; Grandez, 2019, pp. 695-717).

Ciertamente, la apuesta de este modelo no temporal es promover la planificación institucional e interinstitucional, la sinergia de los órganos que forman parte del sistema de justicia, sobre la base del principio de separación y colaboración de los poderes del Estado, y poner en primera una metodología de monitoreo para la sostenibilidad del proceso de mejora continua. Han pasado dieciséis años para cristalizar un espacio de tal naturaleza con sus propias características, más o menos como se pensó en la CERIAJUS y otras propuestas similares. En efecto, se debe anotar que la Comisión 
Consultiva de Reforma del Sistema de Justicia del Poder Ejecutivo tiene en las propuestas de la CERIAJUS (2004), la Defensoría del Pueblo (2006) y el Acuerdo Nacional de Justicia/Poder Ejecutivo (2016-2017), los antecedentes de un órgano de coordinación y conformación interinstitucional de alto nivel ${ }^{19}$. Con anterioridad, desde la visión del Poder Judicial se propuso la implementación de un Centro para la Modernización y Coordinación de la Justicia (2003), como una instancia técnica que tendría un directorio conformado por los máximos representantes de las entidades del sistema de justicia e instituciones de la llamada sociedad civil ${ }^{20}$.

Ahora bien, si la reforma planteada se concibe como una mejora continua y no un fin en sí misma, como una gestión del cambio y medición de su impacto o como un proceso de transformación, para obtener un producto de calidad de las decisiones públicas, en el servicio a las personas/ciudadanos y encaminado a la máxima funcionalidad del sistema de justicia desterrando cualquier resistencia y enquistamiento corporativo/individual, se está formando un valor público enfocado en la persona dentro de un escenario participativo marcado por nuevas perspectivas; $y$ en cuyo caso, el Consejo está obligado a dar resultados y por sus frutos habrá que juzgarlo, por cuanto la idea es dejar de estar de experimento

19 El proyecto de reforma parcial de la Constitución elaborado por la CERIAJUS establecía en su artículo 160 que el Poder Judicial, el Ministerio Público, el Tribunal Constitucional, el Consejo Nacional de la Magistratura y la Academia de la Magistratura mantendrían relaciones de coordinación a efectos de asegurar el cumplimiento adecuado y oportuno de la función estatal de impartir justicia, sin perjuicio de la autonomía constitucionalmente reconocida a cada uno de ellos; y delegaba a una ley orgánica el desarrollo de dicho único articulado. Por parte de la Defensoría del Pueblo léase el Informe Defensorial n. ${ }^{\circ} 109$ (primera recomendación) y del Acuerdo Nacional de Justicia y el Poder Ejecutivo véase el Proyecto Ley n. ${ }^{\circ}$ 1626/2016-PE.

20 Ponencia del presidente del Poder Judicial Dr. Hugo Sivina Hurtado en el Conversatorio Internacional sobre Experiencias de Reforma de la Administración de Justicia, realizado en Lima el 21 de agosto de 2003, hotel Country Club. 
en experimento, de comisión en comisión, haciendo y deshaciendo comisiones o caer en lo mismo ${ }^{21}$.

Si bien el Consejo nació por mandato legal, no por reforma constitucional y sin consenso inicial entre las instituciones del sistema de justicia de hoy en día, el tiempo confirmará su legitimidad de ejercicio; que pasa por superar la salida y ausencia del Tribunal Constitucional ${ }^{22}$ o disminuir cualquier relación tóxica a nivel interórganos constitucionales si existiera. Como fuere, probablemente una reforma constitucional podría reforzar la continuidad y estabilidad del Consejo ante cualquier panorama o intento de debilitar, derogar o extinguir su ley de creación.

Es particularmente gravitante que el Consejo de Reforma del Sistema de Justicia, en su desarrollo haya tenido en cuenta los antecedentes históricos y documentales esbozados en párrafos anteriores, desde una óptica de reforma pluridimensional e integradora, o por lo menos tenga presente como mínimo cuatro grandes dimensiones: normativa, organizativa, implementaciónseguimiento y capacitación-cultura. También sería oportuno que se echara mano de un modo significativo a las propuestas presentadas por el Poder Judicial, perfectible como todo producto humano.

Dentro del marco expuesto y para no exceder el límite de este trabajo, se ponen en mesa algunos aspectos para la marcha reformista del presente siglo:

a) Para no hablar de una reforma de papel o de la «inutilidad» de la reforma, esta debe ser no solo desde sus bases (construida desde abajo hacia arriba), como la creación de una moderna Escuela

21 Nos recuerda la sabia y conocida expresión de Manuel Vicente Villarán en relación con el número de Constituciones: el Perú ha vivido haciendo y deshaciendo Constituciones.

22 Ocurrida durante la presidencia del Dr. Ernesto Blume Fortini y confirmada actualmente en la presidencia de la Dra. Marianella Ledesma Narváez. 
de Magistrados para el acceso a la carrera, también debe tocar la cima del Poder Judicial (desde arriba hacia abajo).

b) Asumir la ideología de la justicia democrática, lo que significa el paso del juez normativista solamente encerrado y enterrado entre sus expedientes y textos legales a aquel juez que no debe ignorar el medio político, social, económico y cultural de la sociedad $^{23}$. Una organización judicial sólida vislumbra tanto la plena función jurisdiccional como la función política y social del juez. Ello implica la necesaria concordancia y conocimiento de la vida política, social y local (e incluso internacional). Ya no estamos en épocas propias de un modelo de juez «aséptico», «legalista», «pasivo», «apolítico» o «no vinculado» (Rico y Salas, 1990, pp. 38-39), el Estado constitucional que se precie de serlo propicia un juez "constitucional», "político», «democrático» $\mathrm{y}$ "próximo» a las partes, que es un juez compenetrado con la sociedad, con el sistema político y su intervención autónoma en el proceso político, diferente a un juez partidario o politizado (que es su negación). Es una evolución nada sencilla porque toca la forma de pensar y razonar de los magistrados.

c) Si la capacitación de los magistrados apunta al fortalecimiento de la independencia e imparcialidad judicial (realización de los valores constitucionales y garantía de los derechos ciudadanos) y por efecto la manutención y consolidación del sistema democrático constitucional, por un juez hacia la interacción con su medio sociopolítico - como habláramos líneas arriba-, se requiere mejorar significativamente los procedimientos de entrenamiento, esto es, la formación y capacitación de los cuerpos

23 En sede nacional, sobre la ideología judicial pueden repasarse los artículos de Sergio Salas Villalobos «¿Qué es la justicia democrática?» (2 de marzo de 2007), «La ideología judicial y la reforma» (2 de febrero de 2007) y «Hacia una justicia democrática» (2001); y el libro de Iván Sequeiros Análisis y comentarios a la Ley Orgánica del Poder Judicial (1996, pp. 25-26). 
judiciales, tanto en la planificación y evaluación como en el contenido curricular. En tanto y en cuanto la formación inicial y continua (en ejercicio) deben estar bajo un modelo de formación profesional para el desarrollo de competencias laborales, un modelo de formación contextual/laboral, desprovistos de teoricismo y academicismo que pueden desviarnos a una formación universitaria, que no corresponde en estricto (Sagués, 1998, p. 122).

d) Corresponde al mismo Poder Judicial priorizar sin demora sus aportes sustantivos sobre el modelo jurisdiccional de la Corte Suprema de Justicia a través del certiorari, un modelo que debe implementarse en el caso peruano a través de determinados filtros: la naturaleza de la pretensión, la materia, la relevancia del caso, la cuantía, y con incidencia en los efectos de la concesión del recurso de casación. Así la Corte Suprema estaría avocada básicamente a su función nomofiláctica, fijar precedentes jurisprudenciales y unificar la jurisprudencia tan necesaria en estos tiempos de litigiosidad.

Igualmente, la necesidad de replantear el «gobierno de los jueces» o "gobierno de la justicia», porque pueden gestarse propuestas externas, así como ha sucedido en el siglo XX en cuestiones de selección, nombramiento y ratificación judicial; $\mathrm{y}$ en el siglo XXI la pérdida de las funciones disciplinarias sobre los integrantes de la judicatura. Una reingenería en la estructura orgánica y funcional de los órganos administrativos del Poder Judicial pertenecientes a la esfera de la Presidencia del Poder Judicial, de la Corte Suprema de Justicia, del Consejo Ejecutivo y de la Gerencia General de este poder público. Un moderno organigrama con un marco ideológico democrático y la performance de sus integrantes acorde con los nuevos tiempos. 
e) En estrecha conexión con el párrafo precedente, una mejor técnica legislativa del principio del stare decisis («estese a lo decidido») ayudaría a superar la diversidad de normas legales regulatorias del precedente judicial. Correspondería dejar también la diversidad de nombres en su empleo, que llama a la confusión: pleno casatorio, acuerdo plenario, sentencia vinculante, sentencia plenaria, precedente obligatorio, doctrina jurisprudencial o pleno jurisdiccional. Pese a ello, cabe destacar que los plenos judiciales han sido considerados como una manifestación de buenas prácticas por la Comisión Interamericana de Derechos Humanos ${ }^{24}$.

f) Poner en primer plano las propuestas legislativas presentadas a fines del año pasado al interior del Consejo para la Reforma del Sistema de Justicia, sobre: i) modificación del Código Procesal Civil, de la Ley n. ${ }^{\circ} 26979$ y la Ley n. ${ }^{\circ} 27584$ sobre el trámite del recurso de casación y limitar el acceso de causas a la Corte Suprema de Justicia, ii) modificación del Código Procesal Civil para la implementación y fortalecimiento de la oralidad en el proceso civil, iii) regulación del uso del expediente judicial electrónico, iv) reforma del recurso de casación en la nueva Ley Procesal del Trabajo, y v) aplicación en sede judicial de los convenios de sustracción internacional de menores.

g) El hecho de que desde hace un decenio el Poder Judicial viene impulsando $-y$ superando gradualmente baches de todo tipo- el uso de la tecnología y la modernidad en el estudio, diseño y construcción del futuro expediente electrónico,

24 Ocurre por ejemplo con el Acuerdo Plenario n. ${ }^{\circ} 001-2016 / C J-116$ sobre los alcances atípicos del delito de feminicidio, Acuerdo Plenario n. ${ }^{\circ}$ 002-2016/CJ-116 sobre lesiones y faltas por daño psíquico y afectación psicológica, y Acuerdo Plenario n. ${ }^{\circ} 005-2016 / C J-116$, sobre delitos de violencia contra la mujer y los integrantes del grupo familiar (ámbito procesal, Ley n. ${ }^{\circ}$ 30364). Véase Comisión Interamericana de Derechos Humanos (2019). 
como muestra de transparencia, rapidez y eficiencia, por cuanto se está hablando del acceso directo en tiempo real a la información de las decisiones judiciales (Lama, 2010, p. A4), hoy es una realidad sin retorno en algunos órganos jurisdiccionales. Su continuidad y expansión dependerá del presupuesto institucional y es especialmente significativa la firma del contrato de préstamo el 27 de noviembre de 2019, entre el Estado peruano y el Banco Mundial para financiar el escalamiento del EJE a nivel nacional, cuyo efecto en su aplicación deberá permitir repotenciar la plataforma de jurisprudencia y los reportes estadísticos. Con bastante razón ante los estragos de la COVID-19, deberá seguirse ampliando el uso de las tecnologías de la información y comunicación (TIC) en el aparato judicial.

h) Una reforma judicial estructural de calidad y confiable, lamentablemente no es barata - guste o no-. Entre el monto del presupuesto solicitado por el Poder Judicial vs. el presupuesto asignado para cada ejercicio fiscal existe una brecha importante, solo en los tres últimos años, para tomar como ejemplo, se ha registrado una tendencia decreciente en cuanto al valor porcentual asignado para los ejercicios fiscales 2017 (66.16 \%), 2018 (64.92\%) y 2019 (50.85\%). Panaroma nocivo para la judicatura, que evidencia lo poco eficiente que ha resultado la aplicación de la Ley n. ${ }^{\circ} 28821$, denominada «Ley de coordinación entre el Poder Judicial y el Poder Ejecutivo para la programación y formulación del presupuesto institucional del Poder Judicial», expedida hace más de dos quinquenios y en la práctica desprovista de los principios constitucionales presupuestarios básicos: competencia y de justicia presupuestaria ${ }^{25}$. Una reestructuración

25 La Ley n. 28821 de 2006, es el resultado de la STC n. ${ }^{\circ}$ 004-2004-CC-TC del 31 de diciembre de 2004, proceso de conflicto de competencia iniciado por el Poder Judicial ante el Poder Ejecutivo, por pretender modificar el proyecto de 
en «rojo» es hueca si no hay una asignación presupuestal suficiente (Hernández, 2007, pp. 543-544). Al respecto, los trabajos preparatorios para la edición XX de la Cumbre Judicial Iberoamericana consideran que uno de los pilares esenciales para el fortalecimiento de la independencia en el ejercicio de la labor jurisdiccional y de los Poderes Judiciales de la región, es la asignación presupuestaria constitucionalmente garantizada y suficiente; y es en esa dirección la puesta en marcha de un protocolo iberoamericano sobre independencia y responsabilidad judicial. Instituciones multilaterales como las Naciones Unidas y la Organización de Estados Americanos abogan no solo por un marco normativo en cada país que consagre un porcentaje mínimo de presupuesto para la judicatura, sino también debe darse un alto grado de prioridad a la asignación de dichos recursos (Organización de los Estados Americanos. Comisión Interamericana de Derechos Humanos, 2013 , p. 25), como también debe ocurrir en temas claves como salud y educación (trilogía: salud, educación y justicia) ${ }^{26}$.

i) En pleno proceso reformista, no se pueden dejar de mencionar los escandalosos actos de corrupción sistemática que le sobrevinieron, dejando prácticamente ninguna zona «exenta» o inmune al galopante y extendido avance de la corrupción supranacional, nacional y subnacional con el tremendo caso de la constructora brasileña Odebrecht (recuérdese también la red Orellana), lo que confirma la lamentable conclusión: «[...] la historia del Perú ha sido en parte la historia de sucesivos ciclos

presupuesto presentando por el Poder Judicial en los términos previstos en el artículo 145 de la Constitución de 1993.

26 Sobre todo ante la cruda realidad del sistema sanitario público, la problemática hospitalaria y las deficiencias educativas puestas en evidencia por el nuevo coronavirus. Situación que originará también una mayor presencia del derecho de la salud y el derecho a la educación en todo enfoque relacionado con la democracia constitucional. 
de corrupción» (Quiroz, 2013, p. 438). Situación extrema que obliga también a una relectura minuciosa sobre cuáles han sido los resultados en cada una de las entidades del sistema de justicia y de la justicia alternativa y el papel de los abogados que viene de tiempo atrás; por cuanto se está demostrando gruesas debilidades $\mathrm{y}$ taras del procedimiento arbitral y de los árbitros ${ }^{27}$. A su turno, ha quedado totalmente confirmado, despejándose cualquier duda, si la hubo, el deficiente y nulo control de los colegios de abogados sobre la conducta e integridad de sus agremiados en el ejercicio profesional. Al revés, para atacar conductas indebidas, maliciosas, dilatorias, temerarias y corruptas se requiere apropiados y mayores mecanismos expeditivos de control, identificando las respectivas responsabilidades de los abogados, de las firmas legales - sean estudios chicos o grandes- y de las mismas asociaciones de abogados. Ayudarían los códigos de conducta profesional según los estándares internacionales ${ }^{28}$.

j) Se debe enfatizar las reformas también en otras instituciones no menos importantes integrantes del universo de la justicia, como es el caso del Tribunal Constitucional y la Contraloría General de la República, por cuanto no han estado fuera del ruido de la crisis del sistema, como ha sucedido con la famosa «repartija» del año 2013 en la elección de los magistrados constitucionales

27 Por ejemplo, ha sido sintomático escuchar en el Primer Encuentro de Centros de Arbitraje e Instituciones Arbitrales 2020, organizado por el Instituto Peruano de Arbitraje (IPA) el 25 y 26 de febrero, la problemática arbitral tan parecida a lo que sucede en ámbitos judiciales, al punto de traernos a la memoria la figura histórica del árbitro con la expresión «jueces árbitros» utilizada expresamente por el antiguo Reglamento de Tribunales y Juzgados de la República de 1845.

28 Recuérdese los «Principios básicos sobre la función de los abogados», aprobados por el Octavo Congreso de las Naciones Unidas sobre Prevención del Delito y Tratamiento del Delincuente, celebrado en La Habana del 27 de agosto al 7 de septiembre de 1990, rubros «obligaciones y responsabilidades» y «actuaciones disciplinarias». Es interesante lo que al respecto señala Vigo (1979). 
y la casi consumada en el 2019 (al punto de originarse nuevas formas democráticas de protestas con el uso de las redes sociales, materializadas en movilizaciones masivas en las calles bajo el hashtag \#TomaLaCalle) $)^{29}$; y la remoción de un contralor general de la República.

\section{REFERENCIAS}

Asociación Civil Transparencia (2018). Hacia un sistema de justicia honesto y eficiente. Versión resumida de los proyectos elaborados por la Comisión Consultiva para la Reforma del Sistema de Justicia R. S. n. ${ }^{\circ}$ 142-2018-PCM. Lima: Asociación Civil Transparencia y Konrad-Adenauer-Stiftung.

Basadre, J. (1983). Historia de la República del Perú. 1822-1933 (t. 2). Lima: Editorial Universitaria.

Belaunde López de Romaña, J. de (2006). La reforma del sistema de justicia. ¿En el camino correcto? Breve balance de su situación actual y de los retos pendientes. Lima: Fundación Konrad Adenauer/Instituto Peruano de Economía Social de Mercado.

Comisión Interamericana de Derechos Humanos (2019). Violencia $y$ discriminación contra mujeres, niñas y adolescentes: buenas prácticas y desafíos en América Latina y en el Caribe. Informe aprobado el 14 de noviembre de 2019.

Consejo Nacional de Justicia (2019). Reunión Iberoamericana de la Agenda 2030 en el Poder Judicial. Agosto 2019, Curitiba, Brasil. Brasilia: Consejo Nacional de Justicia-PNUD.

Cumbre Judicial Iberoamericana (s. f.). Quiénes somos. Recuperado de http://www.cumbrejudicial.org/institucional/quienes-somos

29 Para mayor detalle puede verse Domínguez (2020, pp. 306-323). 
Domínguez, H. (2018). Democracia constitucional. Elementos teóricos, desarrollo jurisprudencial e introducción bibliográfica. Lima: Grijley.

(2019). ¿Ser o no ser del Poder Judicial? Aproximación bibliográfica sobre el proceso de reforma, modernización, reestructuración y refundación de la judicatura nacional. Revista Oficial del Poder Judicial. Revista de Investigación de la Corte Suprema de Justicia de la República del Perú, 9(11), 374-438.

(2020). El sentido de una reforma. Competencias del Tribunal Constitucional y reglas de juego en la renovación de magistrados constitucionales. Gaceta Constitucional, t. 146, 306-323.

Ferrero Costa, R. (2003). Mesa redonda sobre la reforma del Poder Judicial. Revista Jurídica del Perú, (43), p. XIX.

Grandez, P. (2019). La nueva Junta Nacional de Justicia y los desafíos pendientes. En Noveno seminario internacional Proceso y Constitución (pp. 695-717). Lima: Palestra Editores.

Grupo Impulsor del Acuerdo Nacional por la Justicia (ANJ) (2004). Informe final «Políticas de Estado para el cambio estructural en el Poder Judicial». Lima: Poder Judicial del Perú.

Hammergren, L. (2004). La experiencia peruana en reforma judicial: tres décadas de grandes cambios con pocas mejoras. En Pásara, L. (comp.), En busca de una justicia distinta. Experiencias de reforma en América Latina (pp. 289-333). Lima: Consorcio Justicia Viva.

(2007). Envisioning Reform. Improving Judicial Performance in Latin America. University Park, PA: The Pennsylvania State University Press.

Hernández, W. (2007). La reestructuración en «rojo». En Malpartida, V. (comp.), Magistratura: «un poder sin poder», encrucijada y disidencia (pp. 543-544). Lima: Editorial San Marcos. 
Lama, H. E. (18 de noviembre de 2010). ¿Un Poder Judicial virtual? El Comercio, p. A4.

Organización de los Estados Americanos. Comisión Interamericana de Derechos Humanos (2013). Garantías para la independencia de las y los operadores de justicia. Hacia el fortalecimiento del acceso a la justicia y el Estado de derecho en las Américas. Aprobado por la Comisión Interamericana de Derechos Humanos el 5 de diciembre de 2013.

Pásara, L. (31 de julio de 2008). ¿Es posible reformar la justicia? Perú21, p. 9.

(2014). Una reforma imposible. La justicia latinoamericana en el banquillo. Lima: Fondo Editorial de la Pontificia Universidad Católica del Perú.

(2019). De Montesinos a los Cuellos Blancos. La persistente crisis de la justicia peruana. Lima: Planeta.

Quiroz, A. W. (2013). Historia de la corrupción en el Perú. Lima: Instituto de Estudios Peruanos.

Ramos, C. (2019). Historia de la Corte Suprema de Justicia del Perú. Lima: Fondo Editorial del Poder Judicial.

Rico, J. M. y Salas, L. (1990). Independencia judicial en América Latina: replanteamiento de un tema tradicional. San José/ Miami: Centro para la Administración de Justicia/Universidad Internacional de la Florida.

Sagués, N. P. (1998). Las Escuelas Judiciales. México: Universidad Nacional Autónoma de México.

Salas, S. (2001). Hacia una justicia democrática. Lumen. Revista de la Facultad de Derecho de la UNIFÉ, (2), 101-109.

(2 de febrero de 2007). La ideología judicial y la reforma. $L a$ República, p. 18.

(2 de marzo de 2007). ¿Qué es la justicia democrática? La República, p. 18. 
Sequeiros, I. (1996). Análisis y comentarios a la Ley Orgánica del Poder Judicial. Lima: Grijley.

Suprema Corte de Justicia de la Nación (2006). Libro blanco de la reforma judicial. Una agenda para la justicia en México. México D. F.: Suprema Corte de Justicia de la Nación.

Távara, F. (2007). Mensaje del señor presidente del Poder Judicial, doctor Francisco Távara Córdova, en la ceremonia de apertura del Año Judicial 2007. Recuperado de https://www.pj.gob.pe/ wps/wcm/connect/6d9fb1004b56dcd5b5d2b7a05f0807b2/DIS_ FRANCISCO_TAVARA_2007_020107.pdf?MOD=AJPERES\& CACHEID $=6 \mathrm{~d} 9 \mathrm{fb} 1004 \mathrm{~b} 56 \mathrm{dcd} 5 \mathrm{~b} 5 \mathrm{~d} 2 \mathrm{~b} 7 \mathrm{a} 05 \mathrm{f} 0807 \mathrm{~b} 2$

Vigo, R. L. (1979). Ética del abogado. Buenos Aires: Abeledo Perrot. 